\title{
Thermally and Electrochemically Induced Electrode/Electrolyte Interfaces in Solid Oxide Fuel Cells: An AFM and EIS Study
}

\author{
San Ping Jiang ${ }^{\mathrm{z}}$ \\ Fuels and Energy Technology Institute \& Department of Chemical Engineering, Curtin University, Perth WA 6102, \\ Australia
}

In high temperature solid oxide fuel cells (SOFCs), electrode/electrolyte interfaces play a critical role in the electrocatalytic activity and durability of the cells. In this study, thermally and electrochemically induced electrode/electrolyte interfaces were investigated on pre-sintered and in situ assembled $\left(\mathrm{La}_{0.8} \mathrm{Sr}_{0.2}\right)_{0.90} \mathrm{MnO}_{3}$ (LSM) and $\mathrm{La}_{0.6} \mathrm{Sr}_{0.4} \mathrm{Co}_{0.2} \mathrm{Fe}_{0.8} \mathrm{O}_{3-\delta}$ (LSCF) electrodes on $\mathrm{Y}_{2} \mathrm{O}_{3}-\mathrm{ZrO}_{2}$ (YSZ) and $\mathrm{Gd}_{0.2} \mathrm{Ce}_{0.8} \mathrm{O}_{2}$ (GDC) electrolytes, using atomic force microscopy (AFM) and electrochemical impedance spectroscopy (EIS). The results indicate that thermally induced interface is characterized by convex contact rings with depth of $100-400 \mathrm{~nm}$ and diameter in agreement with the particle size of pre-sintered LSM and LSCF electrodes, while the electrochemically induced interfaces under cathodic polarization conditions on in situ assembled electrodes are characterized by particle-shaped contact marks or clusters (50-100 nm in diameter). The number and distribution of contact clusters depend on the cathodic current density as well as the electrode and electrolyte materials. The contact clusters on the in situ assembled LSCF/GDC interface are substantially smaller than that on the in situ assembled LSM/GDC interface likely due to the high mixed ionic and electronic conductivities of LSCF materials. The results show that the electrochemically induced interface is most likely resulting from the incorporation of oxygen species and cation interdiffusion under cathodic polarization conditions. However, the electrocatalytic activity of electrochemically induced electrode/electrolyte interfaces is comparable to the thermally induced interfaces for the $\mathrm{O}_{2}$ reduction reaction under SOFC operation conditions.

(C) The Author(s) 2015. Published by ECS. This is an open access article distributed under the terms of the Creative Commons Attribution 4.0 License (CC BY, http://creativecommons.org/licenses/by/4.0/), which permits unrestricted reuse of the work in any medium, provided the original work is properly cited. [DOI: 10.1149/2.0111510jes] All rights reserved.

Manuscript submitted May 11, 2015; revised manuscript received July 6, 2015. Published July 17, 2015.

Solid oxide fuel cell (SOFC) is one of the most efficient technologies for the conversion of chemical energy of fuels such as hydrogen and natural gas directly into electrical power. It employs a solid oxide electrolyte such as yttria-stabilized zirconia (YSZ) that serves as an ionic conductor in the temperature range between $600^{\circ} \mathrm{C}$ to $1000^{\circ} \mathrm{C}$. The electrolyte separates the cathode from the anode and conducts oxygen ions from the cathode to the anode where they react electrochemically with the fuel. Electrons are then released to an external circuit, which provides a useful source of electrical power. The electrochemical reactions such as $\mathrm{O}_{2}$ reduction at the cathode and $\mathrm{H}_{2}$ oxidation at the anodes occur at the electrode/electrolyte interface regions. ${ }^{1-3}$ Thus, in SOFCs, electrode/electrolyte interfaces play a vital role in the mechanism and kinetics of the electrochemical reactions and in the fundamental understanding of the relationship between the electrochemical processes and microstructure. ${ }^{4-10}$ The cell performance and durability also depend strongly on the microstructural change at the interface under SOFC operation conditions. ${ }^{11,12}$

Lanthanum strontium manganite (LSM) is one of the most common cathode materials for SOFCs because of high electrical conductivity, good thermal and chemical compatibility with YSZ electrolyte, high microstructural stability and high electrocatalytic activity for $\mathrm{O}_{2}$ reduction reaction at high temperatures. ${ }^{13-15}$ However, due to the fact that LSM is a predominant electronic conductor with negligible oxygen ion conductivity, ${ }^{16} \mathrm{O}_{2}$ reduction reaction primarily occurs at the three phase boundaries (TPB), where electrolyte, LSM and $\mathrm{O}_{2}$ gas meet. ${ }^{17-19} \mathrm{O}_{2}$ reduction reaction on LSM cathodes is one of the most important and fundamental electrochemical processes in SOFCs. ${ }^{1,13}$ Due to its unique positions in the fundamental understanding of the kinetics and mechanism of $\mathrm{O}_{2}$ reduction reaction, the interface between LSM electrode and YSZ electrolyte has being attracted significant attention in recent years. ${ }^{12,20-22}$ Early studies show that polarization, either anodic or cathodic, can significantly alter/modify the interface, i.e., the coarsening of the contact rings on the YSZ electrolyte surface. ${ }^{23}$ Matsui et al. quantitatively studied the microstructural change at the LSM/YSZ interface under polarization by focused ion beam-scanning electron microscopy technique and observed the increased roughness of YSZ surface and the formation of closed pores at the LSM/YSZ interface, after cathodic current treatment at $300 \mathrm{~mA}$

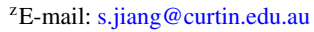

$\mathrm{cm}^{-2} \cdot{ }^{24}$ Further study showed that polarization at a much high current density (e.g., $1.2 \mathrm{~A} \mathrm{~cm}^{-2}$ ) can cause the densification of LSM and formation of nanopores at the interface region. ${ }^{20}$

The interface between LSM and YSZ is further complicated by the reactivity and ionic inter-diffusion between LSM and YSZ during the high temperature sintering process or under SOFC operation conditions. ${ }^{25-27}$ Chen et al. study the thermal stability and reactivity between LSM and YSZ in LSM/YSZ composites using in situ neutron diffraction technique. ${ }^{28}$ The results indicate that the reaction between $\mathrm{LSM}$ and $\mathrm{YSZ}$ starts at $1100^{\circ} \mathrm{C}$, forming $\mathrm{La}_{2} \mathrm{Zr}_{2} \mathrm{O}_{7}, \mathrm{SrZrO}_{3}$ and $\mathrm{MnO}$ at the interface. In the case of LSM cathodes, electrochemical polarization also has a significant effect on the surface chemistry and segregation of LSM in addition to the microstructure and interface between LSM and YSZ. ${ }^{23,25,29}$ Based on the electrochemical behavior of LSM electrodes under the polarization conditions, we proposed that the removal/incorporation of surface passive species such as $\mathrm{SrO}$ under cathodic polarization is responsible for the activation behavior of the LSM on the $\mathrm{O}_{2}$ reduction reaction, while anodic polarization accelerates the $\mathrm{Sr}$ surface segregation, resulting in the deactivation process. ${ }^{30,31}$ The extraordinary effect of polarization on the surface composition and chemistry has been confirmed by Mutoro et al. on ( $\mathrm{LaSr}) \mathrm{CoO}_{3}$ thin film electrodes by in situ synchrotronbased X-ray photoelectron spectroscopy (XPS), ${ }^{32}$ and by Huber et al. on LSM by in situ XPS and secondary ion mass spectroscopy (SIMS). ${ }^{33}$

Lanthanum strontium cobalt ferrite (LSCF) is the best known mixed ionic and electronic conducting (MIEC) perovskite and is one of the most investigated MIEC cathodes for intermediate temperature SOFCs due to its high electrical conductivity and high oxygen exchange coefficient and ionic conductivity. ${ }^{34-37}$ The excellent MIEC properties of LSCF imply that the $\mathrm{O}_{2}$ reduction reaction would occur in the electrode bulk, away from TPB. ${ }^{1}$ However, LSCF is highly reactive to YSZ electrolyte, forming $\mathrm{La}_{2} \mathrm{Zr}_{2} \mathrm{O}_{7}$ and $\mathrm{SrZrO}_{3} \cdot{ }^{38}$ To mitigate the reactivity problem, gadolinian-doped ceria (GDC) is used as the electrolyte or as a diffusion barrier in YSZ electrolyte system. ${ }^{39}$ Wang et al. studied the $\mathrm{Sr}$ and $\mathrm{Zr}$ diffusion in such LSCF/GDC/YSZ system and observed enhanced $\mathrm{Sr}$ diffusion under polarization conditions. ${ }^{40}$ Fan et al. added $1 \% \mathrm{Bi}_{2} \mathrm{O}_{3}$ into LSCF to form a dense LSCF film on the YSZ electrolyte and observed the significant increase in the interface contact area and reduction in the interface ion transfer resistance between cathode and electrolyte. ${ }^{41}$ In the case of MIEC type perovskite 
cathode materials like LSCF, the studies on the electrode/electrolyte interface are relatively rare.

In this study, the formation/evolution of interfaces between the most common cathodes such as LSM and LSCF perovskite and electrolytes such as YSZ and GDC is investigated on both pre-sintered and in situ assembled electrodes. In the case of in situ assembled electrodes, electrode coatings were directly assembled at test temperatures of $800^{\circ} \mathrm{C}$ without conventional high temperature sintering process. The results clearly demonstrate that electrochemical polarization can induce the electrode/electrolyte interfaces on LSM/YSZ and LSM/GDC and in less extent on LSCF/GDC. The electrocatalytic activities of electrochemically induced interfaces are comparable or better than that of thermally induced interfaces for the $\mathrm{O}_{2}$ reduction reaction.

\section{Experimental}

Materials and electrode preparation.-Zirconia electrolyte discs were prepared from $8 \mathrm{~mol} \% \mathrm{Y}_{2} \mathrm{O}_{3}-\mathrm{ZrO}_{2}$ (YSZ, Tosoh, Japan) by diepressing, followed by sintering at $1550^{\circ} \mathrm{C}$ in air for $4 \mathrm{~h}$. Gadoliniadoped ceria $\left(\mathrm{Gd}_{0.2} \mathrm{Ce}_{0.8} \mathrm{O}_{2}\right.$, GDC) was synthesized by solid state reaction from the mixture of $\mathrm{CeO}_{2}\left(99.9 \%\right.$, Sigma-Aldrich) and $\mathrm{Gd}_{2} \mathrm{O}_{3}$ (99.9, Sigma-Aldrich). GDC powders were ballmilled and die-pressed into discs, followed by sintering at $1600^{\circ} \mathrm{C}$ for $4 \mathrm{~h}$ in air. The electrolyte discs were $\sim 1 \mathrm{~mm}$ thick and $\sim 20 \mathrm{~mm}$ in diameter. A-site deficient $\left(\mathrm{La}_{0.8} \mathrm{Sr}_{0.2}\right)_{0.90} \mathrm{MnO}_{3}$ (LSM) powder was prepared by a coprecipitation technique and sintered at $900^{\circ} \mathrm{C}$. XRD showed the formation of single perovskite phase of the powder. LSM electrode ink was prepared and applied at the center of the YSZ electrolyte discs by slurry painting and sintered at $1150^{\circ} \mathrm{C}$ for $2 \mathrm{~h}$ in air. The as-sintered LSM electrodes were denoted as pre-sintered LSM. The area of LSM electrode was $\sim 0.5 \mathrm{~cm}^{2}$ and the thickness of the coating was $\sim 15 \mu \mathrm{m}$. Platinum paste was symmetrically painted on the center of opposite side of the YSZ discs to form the counter electrode and the reference electrode was painted as a ring around the counter electrode. The gap between the counter and reference electrodes was $\sim 4 \mathrm{~mm}$. The platinum electrodes were sintered at $900^{\circ} \mathrm{C}$ for $2 \mathrm{~h}$.

In situ assembled LSM electrodes without pre-sintering were also prepared. In this case, LSM electrode ink was applied to YSZ electrolyte disc with pre-sintered Pt counter and reference electrodes. After drying, LSM electrodes were assembled in the test rig for the electrochemical testing. LSM electrodes without pre-sintering were denoted as in situ assembled LSM. Pre-sintered and in situ assembled LSM electrodes were also prepared on GDC electrolytes, in similar way as that of pre-sintered and in situ assembled LSM/YSZ cells.

$\mathrm{La}_{0.6} \mathrm{Sr}_{0.4} \mathrm{Co}_{0.2} \mathrm{Fe}_{0.8} \mathrm{O}_{3-\delta}$ (LSCF, Fuel Cell Materials) electrode ink was applied to GDC electrolyte discs by slurry painting. Pre-sintered LSCF electrodes were prepared by sintering the as-painted LSCF electrodes at $1100^{\circ} \mathrm{C}$ in air for $2 \mathrm{~h}$. In situ assembled LSCF electrodes were obtained by direct assembly of the as-painted LSCF electrodes on GDC electrolyte substrates with pre-sintered Pt counter and reference electrodes in fuel cell test rig without pre-sintering at $1100^{\circ} \mathrm{C}$ in air. $\mathrm{Pt}$ mesh was used as current collector for the working and counter electrodes.

Characterization.- Electrochemical polarization and impedance measurements were conducted in a three-electrode set-up. Early studies show that cell configurations with symmetric electrode geometry and reference electrode positioned at the side of the working electrode and away from the exits of fuel and oxidant gases are suitable for the accurate performance evaluation of planar SOFCs and the cathodic and anodic polarization can be accurately separated if the thickness of the electrolytes is $\geq \sim 250 \mu \mathrm{m}){ }^{42}$ The LSM or LSCF cathodes were polarized at current densities of $100,200,500$ or $1000 \mathrm{mAcm}^{-2}$ in air for $3 \mathrm{~h}$ at $800^{\circ} \mathrm{C}$. Cathodic potential was measured against $\mathrm{Pt}$ air reference electrode. The polarization was interrupted to make the electrochemical impedance spectroscopy (EIS) measurements. EIS was obtained using Solartron 1260 frequency response analyzer in conjunction with a Solartron 1287 electrochemical interface from
$100 \mathrm{kHz}$ to $0.1 \mathrm{~Hz}$ at a signal amplitude of $10 \mathrm{mV}$. Electrode polarization resistance, $R_{\mathrm{E}}$ was measured by the differences between the high and low frequency intercepts. Electrode ohmic resistance, $R_{\Omega}$ was obtained from the high frequency intercepts on the impedance curves.

The topography and microstructural change at the electrode/ electrolyte interfaces before and after the polarization treatments were investigated using tapping-mode atomic force microscopy (AFM). The examination was done under ambient conditions using a Digital Instruments Nanoscope IIIA microscope. To examine the electrode/electrolyte interface, the electrode coatings were removed by immersing in $1 \mathrm{M} \mathrm{HCl}$ solution for $30 \mathrm{~min}$ in an ultrasonic bath at room temperature. Prior to AFM examination, samples were treated with ethanol in an ultrasonic bath at room temperature for $\sim 5$ minutes and then cleaned thoroughly with distilled water. This is to remove any residues or impurities that may have stained onto the electrode/ electrolyte interface. Care was exercised when handling the samples to avoid any accidental contamination of the electrode/electrolyte interface.

\section{Results and Discussion}

LSM/YSZ interface. - Figure 1 shows the impedance curves for the $\mathrm{O}_{2}$ reduction reaction on pre-sintered LSM cathode on YSZ electrolyte under a cathodic current density of $500 \mathrm{~mA} \mathrm{~cm}^{-2}$ at $800^{\circ} \mathrm{C}$. The initial $R_{\mathrm{E}}$ for the $\mathrm{O}_{2}$ reduction reaction before the polarization treatment is $17.4 \Omega \mathrm{cm}^{2}$, and decreases drastically with the cathodic polarization
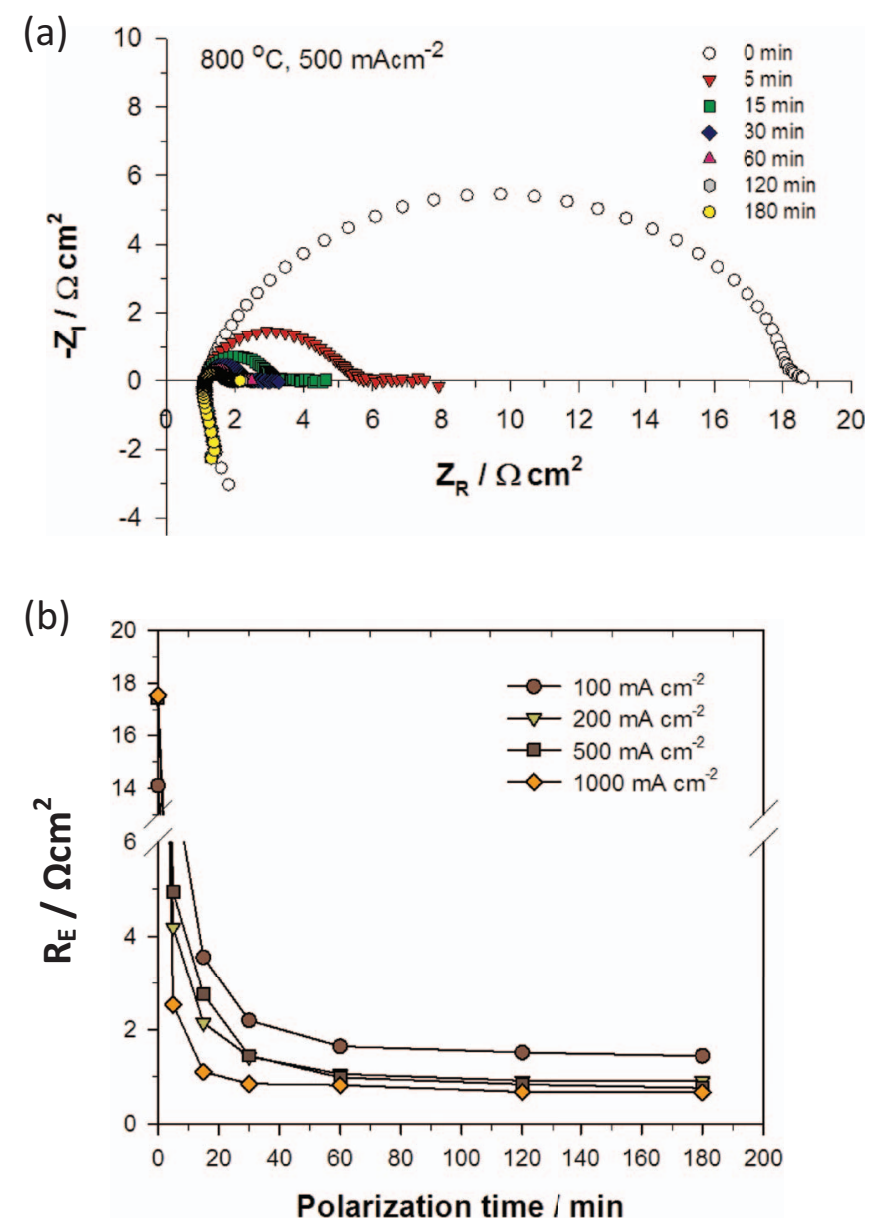

Figure 1. (a) Impedance curves of $\mathrm{O}_{2}$ reduction reaction on pre-sintered LSM cathodes on YSZ electrolyte as a function of cathodic polarization currents of $500 \mathrm{mAcm}^{-2}$ at $800^{\circ} \mathrm{C}$ and (b) the change of $\mathrm{R}_{\mathrm{E}}$ as a function of polarization time, measured at different current densities and $800^{\circ} \mathrm{C}$. 
(a)

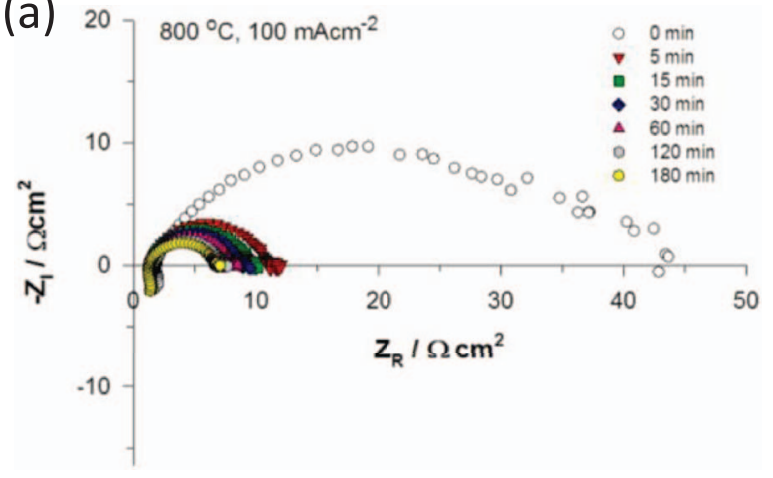

(c)

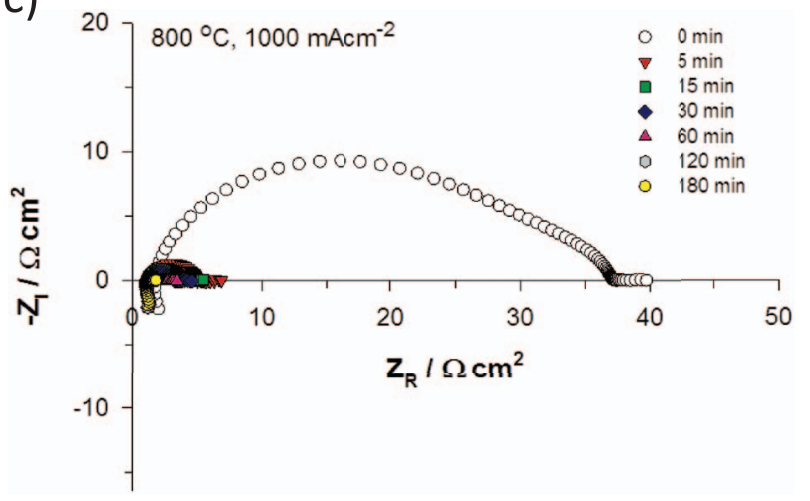

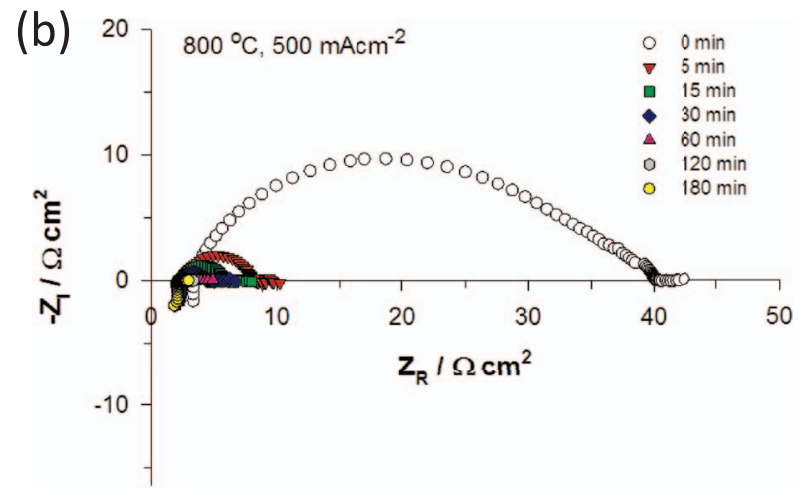

(d)

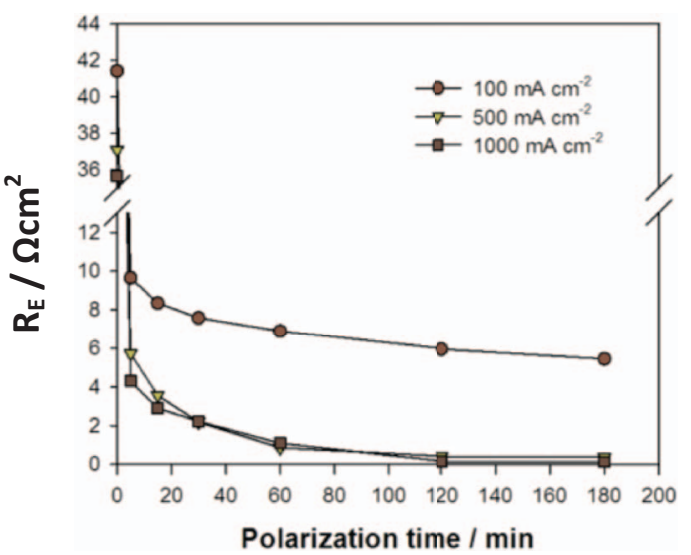

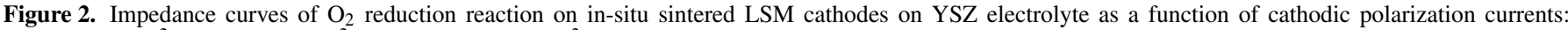
(a) $100 \mathrm{mAcm}^{-2}$, (b) $500 \mathrm{mAcm}^{-2}$, and (c) $1000 \mathrm{mAcm}^{-2}$ at $800{ }^{\circ} \mathrm{C}$. The change of $\mathrm{R}_{\mathrm{E}}$ as a function of polarization time is shown in (d).

current passage. For example, after polarized at $500 \mathrm{mAcm}^{-2}$ for 5 and $180 \mathrm{~min}, R_{\mathrm{E}}$ is 4.3 and $0.8 \Omega \mathrm{cm}^{2}$, respectively. The reduction in $R_{E}$ is clearly due to the activation effect of polarization on the electrochemical activity of LSM-based electrodes. ${ }^{30,33,43-45}$ The reduction in $R_{\mathrm{E}}$ also depends on the current density. However, as shown in Fig. 1b, further increase of the current above $200 \mathrm{~mA} \mathrm{~cm}^{-2}$ has negligible effect on the reduction of $R_{\mathrm{E}}$ for the reaction at the pre-sintered LSM/YSZ interface. As expected, $\mathrm{R}_{\Omega}$ is more or less the same and does not change with the cathodic polarization current passage.

Figure 2 is the impedance responses of the in situ assembled LSM cathodes on YSZ electrolyte as a function of polarization time, measured under different current densities at $800^{\circ} \mathrm{C}$. The $\mathrm{O}_{2}$ reduction reaction on the in situ assembled LSM/YSZ interface is characterized by a very large and depressed impedance arc with no clear separation of impedance arcs at low and high frequencies. The initial $R_{\mathrm{E}}$ for the in situ assembled LSM cathode without high temperature pre-sintering is $36-42 \Omega \mathrm{cm}^{2}$, which is substantially higher than $14-17 \Omega \mathrm{cm}^{2}$ obtained on pre-sintered LSM electrodes measured under identical conditions. However, similar to that observed for the reaction on presintered LSM, the size of the impedance arc decreases significantly with the cathodic polarization. After applying a cathodic current of $500 \mathrm{mAcm}^{-2}$ for $5 \mathrm{~min}, R_{\mathrm{E}}$ of the in situ assembled LSM decreased from $37.1 \Omega \mathrm{cm}^{2}$ to $5.6 \Omega \mathrm{cm}^{-2}$, a $85 \%$ reduction in $R_{\mathrm{E}}$. At the end of the polarization treatment $\left(500 \mathrm{mAcm}^{-2}\right.$ for $\left.180 \mathrm{~min}\right), R_{\mathrm{E}}$ is reduced to $0.4 \Omega \mathrm{cm}^{2}$, substantially smaller than the initial $R_{\mathrm{E}}$ before the cathodic polarization (Fig. 2b). This value is also smaller than $0.8 \Omega \mathrm{cm}^{2}$ for the $\mathrm{O}_{2}$ reduction reaction on the pre-sintered LSM/YSZ interface polarized under the same current density for $3 \mathrm{~h}$ (Fig. 1a). As shown in Fig. 2d, further increase of the cathodic current densities to $1000 \mathrm{mAcm}^{-2}$ does not bring significant benefits to the reduction in $R_{\mathrm{E}}$. The impedance behavior under cathodic polarization shows typical activation process of the LSM-based cathodes under cathodic polarization (Fig. 2d), ${ }^{30}$ similar to that observed on pre-sintered LSM electrodes (Fig. 1).

Figure 3 compares the polarization behavior of the pre-sintered and in situ assembled LSM cathodes on YSZ electrolyte for the $\mathrm{O}_{2}$ reduction reaction, measured at $500 \mathrm{mAcm}^{-2}$ and $800^{\circ} \mathrm{C}$. In the case of the reaction on pre-sintered LSM electrode, the cathodic polarization potential $\left(\mathrm{E}_{\mathrm{Cathode}}\right)$ is characterized by a rapid decrease at initial stage with cathodic current passage, followed by a region where the decrease in $\mathrm{E}_{\text {Cathode }}$ is much slower. The $\mathrm{R}_{\Omega}$ is essentially constant and does not change with the cathodic polarization (Fig. 3a). The polarization potential for $\mathrm{O}_{2}$ reduction on the in situ assembled LSM electrode behaves similarly to that on the pre-sintered LSM electrodes. The only visible differences from that observed for the reaction on pre-sintered LSM is an initial decrease of the $R_{\Omega}$ for the reaction on the in situ assembled LSM electrode (Fig. 3b). Initial $R_{\Omega}$ is 3.33 $\Omega \mathrm{cm}^{2}$ and decreases to $2.1 \Omega \mathrm{cm}^{2}$ after polarization at $500 \mathrm{mAcm}^{-2}$ for $15 \mathrm{~min}$, becoming more or less stable with further current passage. This indicates that the cathodic polarization current improves the intimate contact between the assembled LSM particles and YSZ electrolyte. The significant decrease of $\mathrm{E}_{\text {Cathode }}$ and $R_{\mathrm{E}}$ under cathodic current passage is consistent with the activation behavior of LSM cathodes $^{30,33,43-45}$ and confirms the activation effect of the cathodic polarization on the electrochemical activity of both in situ assembled and pre-sintered LSM electrodes.

Figure 4 shows the AFM micrographs of the YSZ electrolyte surface in contact with the pre-sintered LSM electrodes after cathodic polarization at different current densities and $800^{\circ} \mathrm{C}$. Before the electrochemical polarization, AFM micrographs clearly show the formation of contact convex rings with sharp edge on the surface of YSZ electrolyte grains (Figs. 4d and 4e). The depth of the rings is $100-400 \mathrm{~nm}$ with width in the range of 70 to $100 \mathrm{~nm}$. The diameter of majority of the convex rings is in the range of $0.6-1.0 \mu \mathrm{m}$, in agreement with the particle size of pre-sintered LSM. The convex contact rings are formed 
(a)

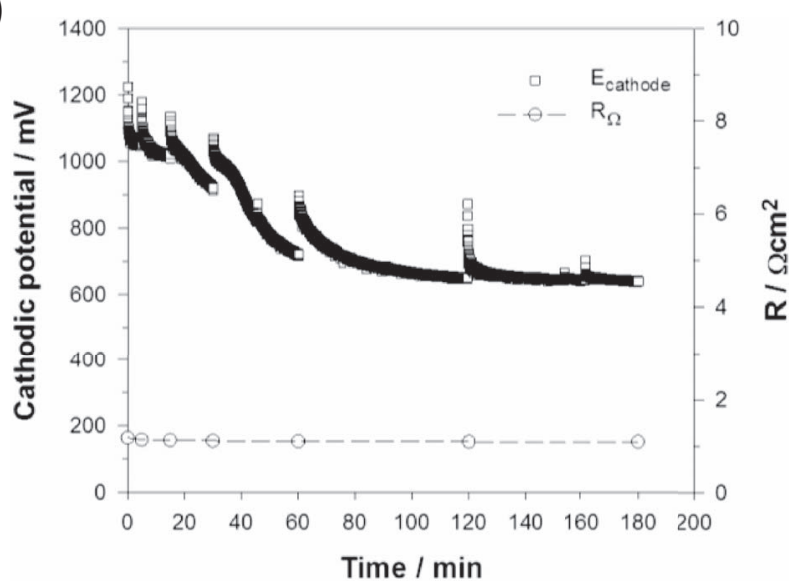

(b)

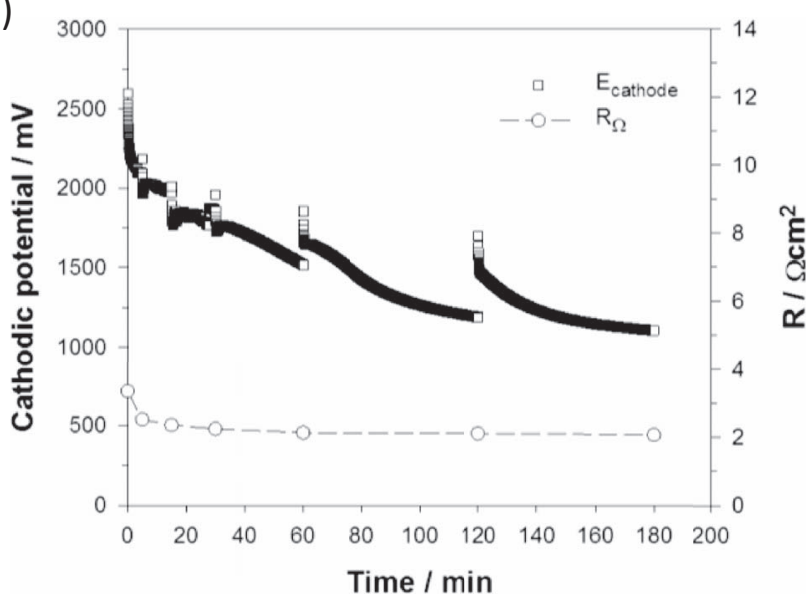

Figure 3. Polarization curves of $\mathrm{O}_{2}$ reduction reaction on (a) pre-sintered and (b) in situ sintered LSM cathodes on YSZ electrolyte, measured at $500 \mathrm{~mA}$ $\mathrm{cm}^{-2}$ and $800^{\circ} \mathrm{C}$ in air.

during the sintering stage of LSM electrodes as the LSM electrode has not been subjected to the polarization treatment. The formation of contact convex rings at the LSM/YSZ interface is most likely due to the cation interdiffusion between YSZ and LSM during the high temperature sintering. ${ }^{25} \mathrm{As} \mathrm{A}$-site deficient composition is used in the present study, the formation of lanthanum zirconate will be depressed as compared to the stoichiometrical LSM. ${ }^{46}$ After cathodic polarization treatment for $3 \mathrm{~h}$, the sharp edge of the crater rings disappears and rings are flattened and grow outward. The growth and widening of the convex rings increases with the increase of the cathodic polarization current densities (see Fig. 4c), consistent with previous results. ${ }^{23}$

Figure 5 is the AFM micrographs of the in situ assembled LSM/YSZ interface before and after the cathodic polarization treatment at $800^{\circ} \mathrm{C}$. Before the polarization, the YSZ electrolyte surface is clean with smooth YSZ grains and grain boundaries (Fig. 5e). After polarization in air for $3 \mathrm{~h}$, there is a clear formation of nano-sized contact marks or islands on the surface of YSZ electrolyte, as shown by circles in the figure. With the increase of the cathodic polarization current densities, the number of contact marks or islands grows. In the case of in situ assembled LSM on YSZ electrolyte after polarized at $1000 \mathrm{mAcm}^{-2}$ for $3 \mathrm{~h}$, the YSZ electrolyte surface are covered by contact clusters (Fig. 5c). The clusters consist of numerous particleshaped contact marks with size of 50-100 nm (Fig. 5d). The YSZ electrolyte surface between the contact clusters is clean, indicating that the contact clusters are the contact points between the in situ assembled LSM particles and YSZ electrolyte. This clearly indicates that the contact marks or clusters formed on the surface of YSZ electrolyte
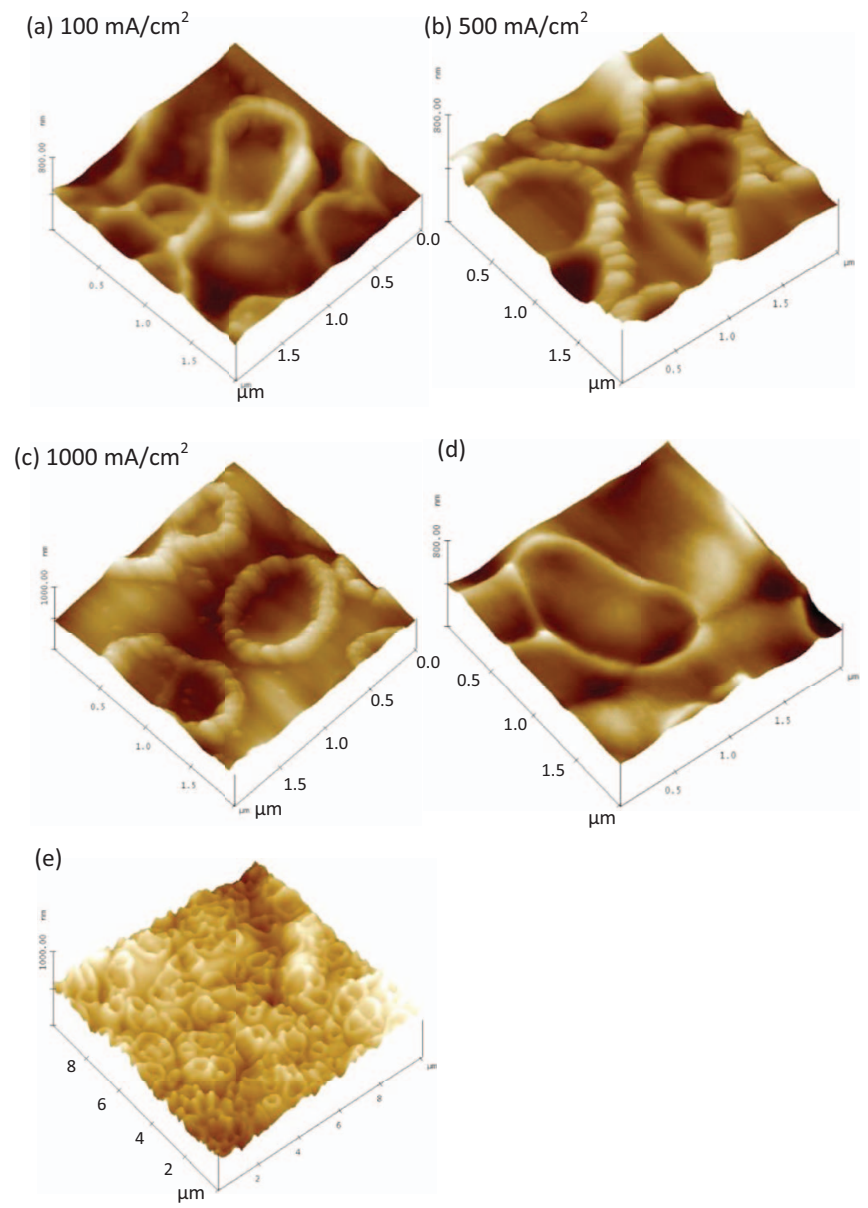

Figure 4. AFM micrographs of YSZ electrolyte surface in contact with presintered LSM electrodes after polarized at (a) $100 \mathrm{mAcm}^{-2}$; (b) $500 \mathrm{mAcm}^{-2}$; (c) $1000 \mathrm{mAcm}^{-2}$ and $800^{\circ} \mathrm{C}$ for $3 \mathrm{~h}$. LSM electrode was pre-sintered at $1150^{\circ} \mathrm{C}$ in air before the test and was removed by $\mathrm{HCl}$ treatment. YSZ surface in contact with a pre-sintered LSM electrode prior to the polarization treatment is given in $(\mathrm{d}, \mathrm{e})$.

are induced by the electrochemical polarization current generated for the oxygen reduction reaction.

LSM/GDC interface.- Figure 6 shows the impedance curves for the $\mathrm{O}_{2}$ reduction reaction on pre-sintered LSM cathode on GDC electrolyte under different current densities at $800^{\circ} \mathrm{C}$. The impedance responses for the $\mathrm{O}_{2}$ reduction reaction on pre-sintered LSM/GDC interface are characterized by two separated impedance arcs at low and high frequencies. Similar to that observed on the pre-sintered LSM/YSZ interface, $R_{\mathrm{E}}$ decreases rapidly upon the application of a cathodic polarization, while the $R_{\Omega}$ is independent of the cathodic polarization current treatment. The cathode polarization is primarily on the reduction of the electrode polarization resistance associated with the low frequencies.

The impedance responses for the $\mathrm{O}_{2}$ reduction reaction on the in situ assembled LSM cathode on GDC electrolyte appear to be different from that on pre-sintered LSM/GDC interface, as shown in Fig. 7. The size of the impedance arcs decreases with the cathodic polarization current passage time, but the reduction in the $R_{\mathrm{E}}$ is gradual and substantially slower than that observed on pre-sintered LSM/GDC interface. For example, the initial $R_{\mathrm{E}}$ for the reaction on an in situ assembled LSM/GDC is $3 \Omega \mathrm{cm}^{2}$ and decreases to $2.3 \Omega \mathrm{cm}^{2}$ after polarization at $100 \mathrm{~mA} \mathrm{~cm}^{-2}$ for $5 \mathrm{~min}$. The final $R_{\mathrm{E}}$ is $1.3 \Omega \mathrm{cm}^{2}$ after polarization for $3 \mathrm{~h}$, a $43 \%$ reduction in $\mathrm{R}_{\mathrm{E}}$. In the case of pre-sintered LSM/GDC interface, the initial $R_{\mathrm{E}}$ for the reaction is $20 \Omega \mathrm{cm}^{2}$ and decreases to 5.3 and $2.5 \Omega \mathrm{cm}^{2}$ after polarization at $100 \mathrm{~mA} \mathrm{~cm}^{-2}$ for 

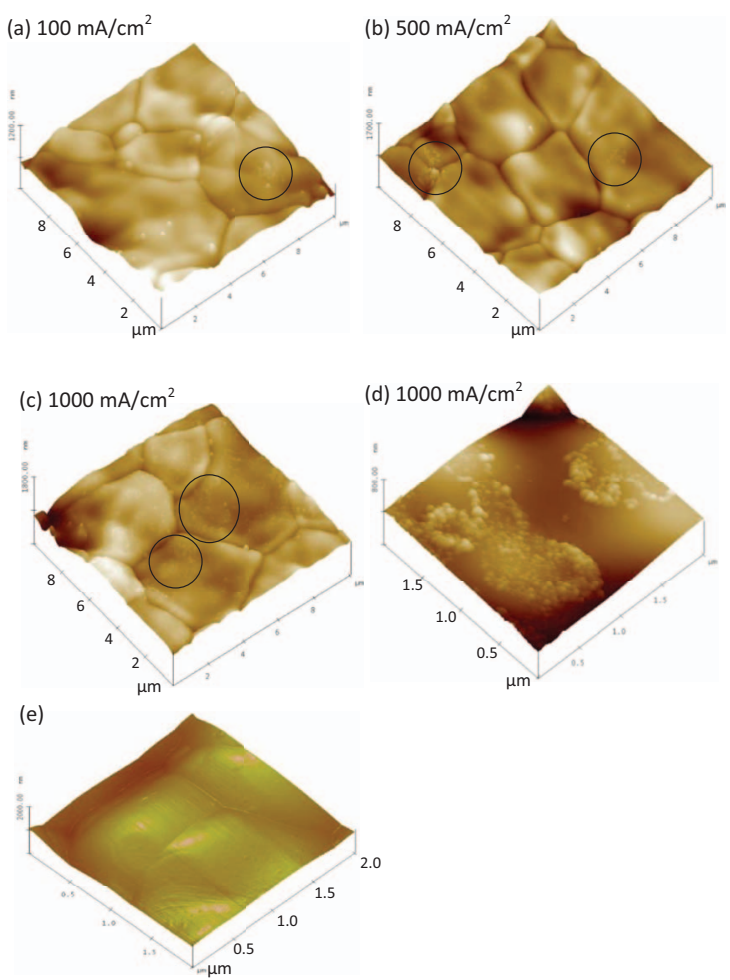

Figure 5. AFM micrographs of the in situ sintered LSM/YSZ electrolyte interface after polarized at (a) $100 \mathrm{mAcm}^{-2}$; (b) $500 \mathrm{mAcm}^{-2}$; (c, d) 1000 $\mathrm{mAcm}^{-2}$ and $800^{\circ} \mathrm{C}$ for $3 \mathrm{~h}$. A clean YSZ electrolyte surface is shown in (e). LSM electrode was removed by $\mathrm{HCl}$ treatment.
5 and 180 min, a $88 \%$ reduction in $R_{\mathrm{E}}$. Similar to that observed on the in situ assembled LSM/YSZ interface, $R_{\Omega}$ also decreases with cathodic current passage. For example, in the case of an in situ assembled LSM/GDC interface, the initial $\mathrm{R}_{\Omega}$ is $1.9 \Omega \mathrm{cm}^{2}$ and decreases to $1.05 \Omega \mathrm{cm}^{2}$ after polarization at $1000 \mathrm{mAcm}^{-2}$ for $3 \mathrm{~h}$.

Figure 8 is the AFM micrographs of the GDC electrolyte surface in contact with the pre-sintered LSM electrodes after cathodic polarization at different current densities and $800^{\circ} \mathrm{C}$. There is a significant change of the contact convex rings on the GDC electrolyte surface, similar to that observed on the pre-sintered LSM/YSZ interface. After polarization treatment, the convex rings are roughened with widened and broken edges. The significant change in the contact convex rings indicates that the $\mathrm{O}_{2}$ reduction reaction primarily occurs on TPB, consistent with the similar polarization and impedance behavior of the reaction observed on pre-sintered LSM electrodes on both GDC and YSZ electrolytes.

Figure 9 is the AFM micrographs of the GDC electrolyte surface in contact with the in situ assembled LSM electrodes after cathodic polarization at different current densities and $800^{\circ} \mathrm{C}$ for $3 \mathrm{~h}$. Similar to that observed on the in situ assembled LSM/YSZ interface, contact marks or clusters are also formed on the GDC electrolyte surface and the number of the contact clusters increase with the polarization current density. However in addition to the formation of the contact marks, there is also formation of nano-indents on the GDC surface (Fig. 9d). Contact clusters and nano-indents appear to spread uniformly to the whole GDC electrolyte surface. This can be seen more clearly for the reaction on the in situ sintered LSM/GDC interface after cathodic current passage at $1000 \mathrm{mAcm}^{-2}$ (Figs. 9c and 9d). The more uniformly formed LSM/GDC interface nano-sized contacts may explain the much slower and gradual reduction of $R_{\mathrm{E}}$ as a function of the cathodic polarization time, as compared to that on the in situ assembled LSM/YSZ interface. (a)

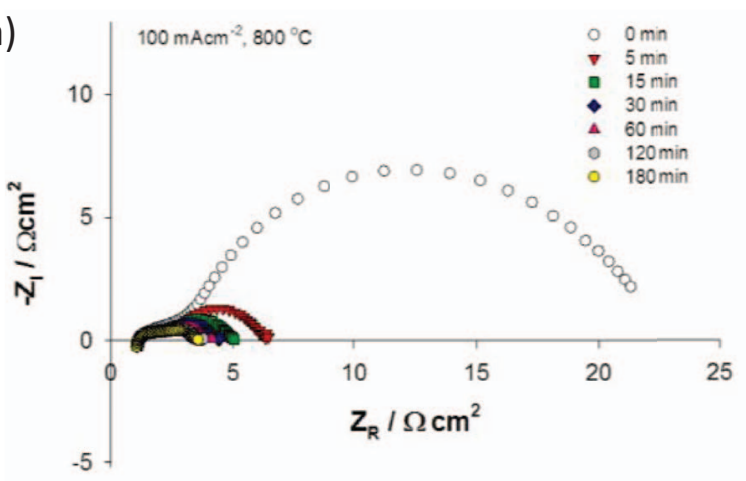

(c)

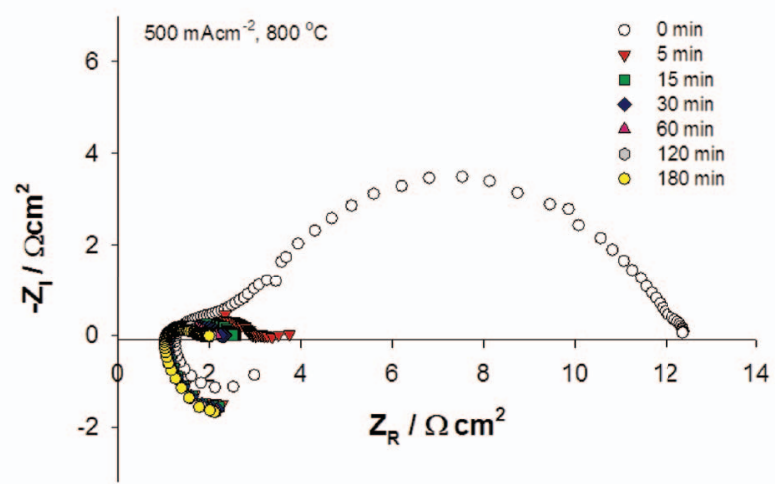

(b)

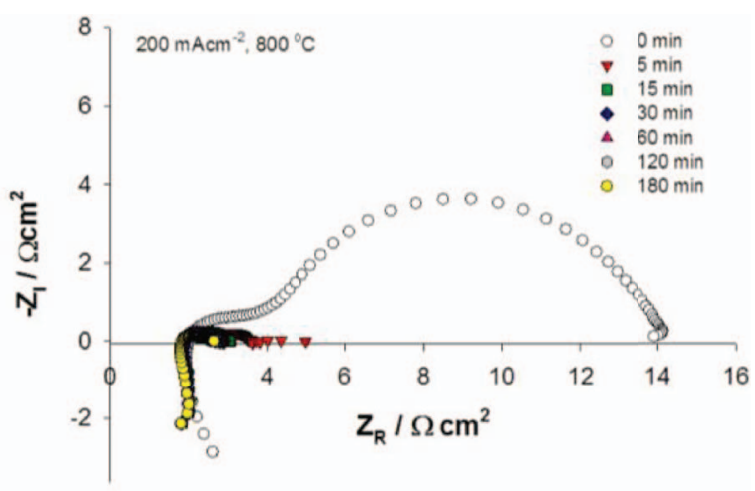

(d)

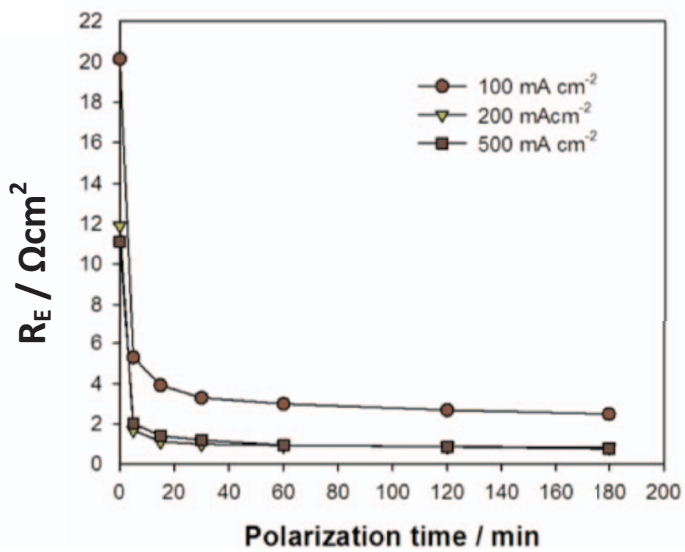

Figure 6. Impedance curves of oxygen reduction on pre-sintered LSM cathodes on GDC electrolyte as a function of cathodic polarization currents: (a) $100 \mathrm{mAcm}^{-2}$, (b) $200 \mathrm{mAcm}^{-2}$, and (c) $500 \mathrm{mAcm}^{-2}$ at $800^{\circ} \mathrm{C}$. The change of $R_{\mathrm{E}}$ as a function of polarization time is shown in (d). 
(a)

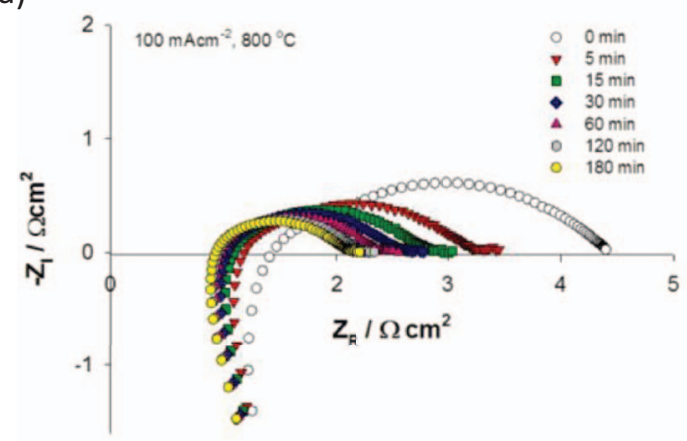

(c)

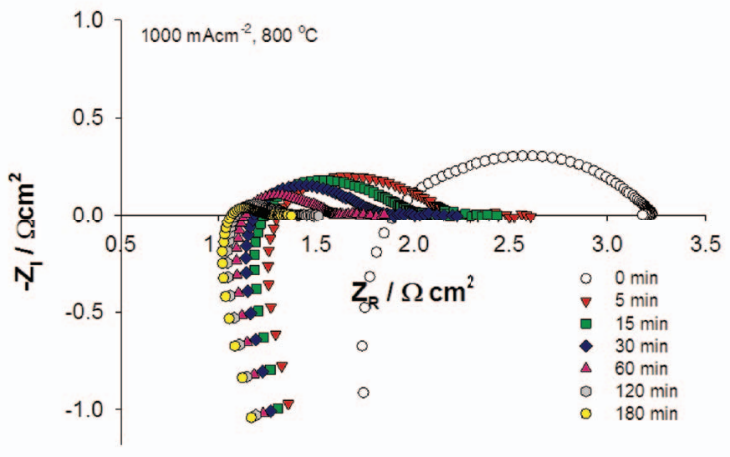

(b)

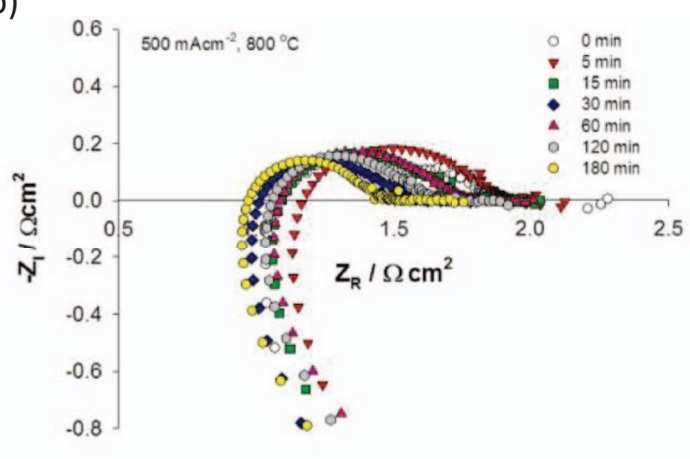

(d)

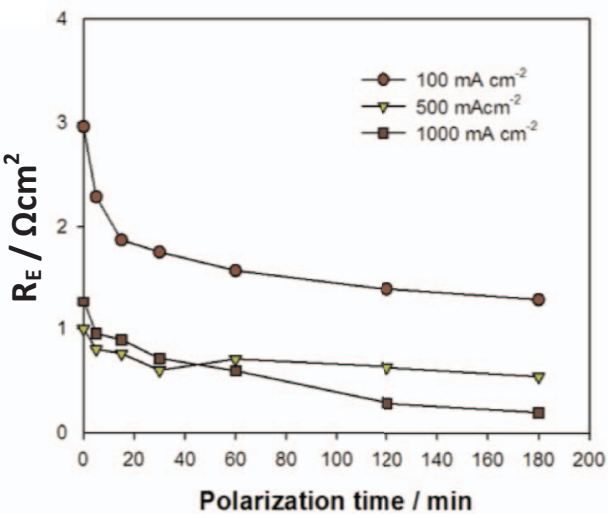

Figure 7. Impedance curves of oxygen reduction on in situ sintered LSM cathodes on GDC electrolyte as a function of cathodic polarization currents: (a) $100 \mathrm{mAcm}^{-2}$, (b) $500 \mathrm{mAcm}^{-2}$, and (c) $1000 \mathrm{mAcm}^{-2}$ at $800^{\circ} \mathrm{C}$. The change of $R_{\mathrm{E}}$ as a function of polarization time is shown in (d).

LSCF/GDC interface.- Figure 10 shows the impedance responses of the $\mathrm{O}_{2}$ reduction reaction on pre-sintered LSCF/GDC interface as a function of cathodic current passage at different current densities and $800^{\circ} \mathrm{C}$. The impedance responses for the $\mathrm{O}_{2}$ reduction on
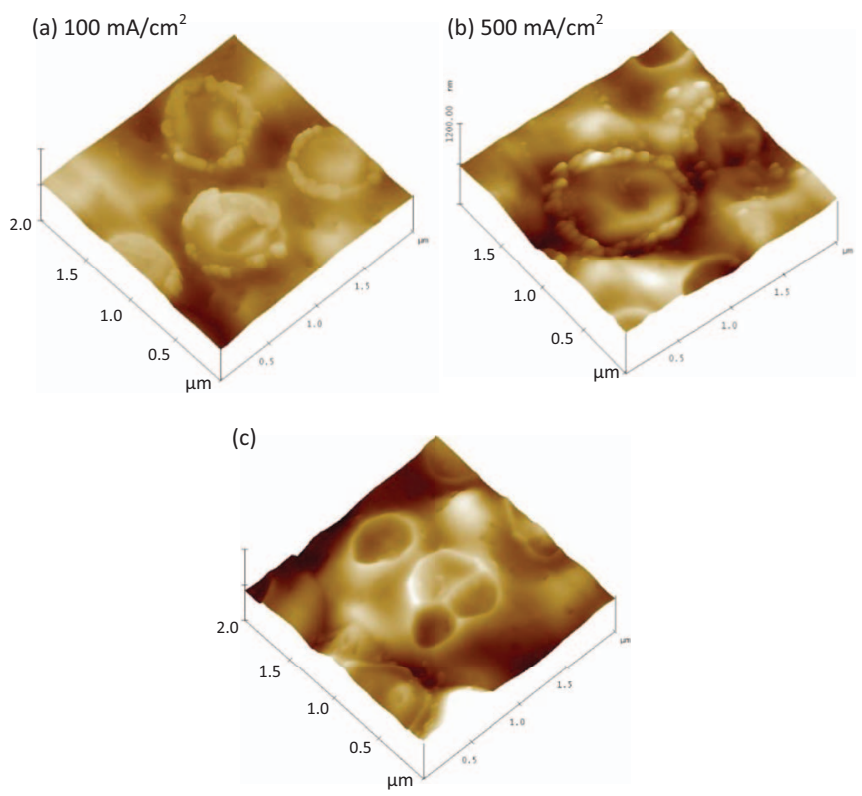

Figure 8. AFM micrographs of the pre-sintered LSM/GDC interfaces after polarized at (a) $100 \mathrm{mAcm}^{-2}$; (b) $500 \mathrm{mAcm}^{-2}$ and $800^{\circ} \mathrm{C}$ for $3 \mathrm{~h}$. LSM electrode was pre-sintered at $1150^{\circ} \mathrm{C}$ and was removed by $\mathrm{HCl}$ treatment after the polarization treatment. GDC electrolyte surface in contact with a pre-sintered LSM before the polarization treatment is given in (c). pre-sintered LSCF electrodes are characterized by a depressed arc and an inductance loop at high frequencies, which is mainly induced by contact Pt wires and the high temperature furnace wires. ${ }^{47,48}$ The change in the size of impedance arcs is very small with the cathodic polarization time at $800^{\circ} \mathrm{C}$, very different from that observed on presintered LSM/GDC interface (see Fig. 6). As shown in Fig. 10a, $R_{\mathrm{E}}$ changes slightly from 0.10 to $0.12 \Omega \mathrm{cm}^{2}$, while and $R_{\Omega}$ decreases from 1.54 to $1.20 \Omega \mathrm{cm}^{2}$ after polarized at $100 \mathrm{mAcm}^{-2}$ for $3 \mathrm{~h}$. The variation of the $R_{\Omega}$ value with the cathodic polarization conditions has been commonly observed for the pre-sintered LSCF electrodes. ${ }^{49}$

Similar to that observed for the pre-sintered LSM/GDC interface, contact convex rings were also observed on GDC electrolyte surface after removal of the pre-sintered LSCF electrodes (Figs. 11d and 11e). The size of the convex contact rings is in the range of $0.2-0.5 \mu \mathrm{m}$, smaller than that obtained on pre-sintered LSM/GDC interface. The smaller contact ring is due to the fine LSCF electrode powders. There are some changes in the morphologies of the convex contact rings on the GDC electrolyte surface after the cathodic polarization treatment, however, the change in the morphology and topography is minor and very small, and the convex rings are essentially intact, very different from the broken rings as observed on the pre-sintered LSM/GDC interface under identical polarization conditions. The negligible change of the contact convex rings on the pre-sintered LSCF/GDC interface is consistent with the excellent mixed electronic and ionic conductivities and high electrocatalytic activity of LSCF perovskite materials for the $\mathrm{O}_{2}$ reduction reactions at intermediate temperatures. ${ }^{50-56}$ This in turn indicates that $\mathrm{O}_{2}$ reduction reaction would occur mainly in the bulk of the electrodes away from the electrode/electrolyte interface.

Figure 12a is the impedance responses of the $\mathrm{O}_{2}$ reduction on the in situ assembled LSCF electrode on GDC electrolyte under a cathodic current of $1000 \mathrm{mAcm}^{-2}$ at $800^{\circ} \mathrm{C}$. Despite the high polarization current, the electrode impedance of the in situ assembled LSCF behaves very similarly to that of the pre-sintered LSCF. $R_{\mathrm{E}}$ remains more or less the same, while $R_{\Omega}$ is reduced from 1.48 to $1.07 \Omega \mathrm{cm}^{2}$ after polarized for $3 \mathrm{~h}$. Initial $R_{\mathrm{E}}$ is $0.13 \Omega \mathrm{cm}^{2}$ and decreases slightly to 

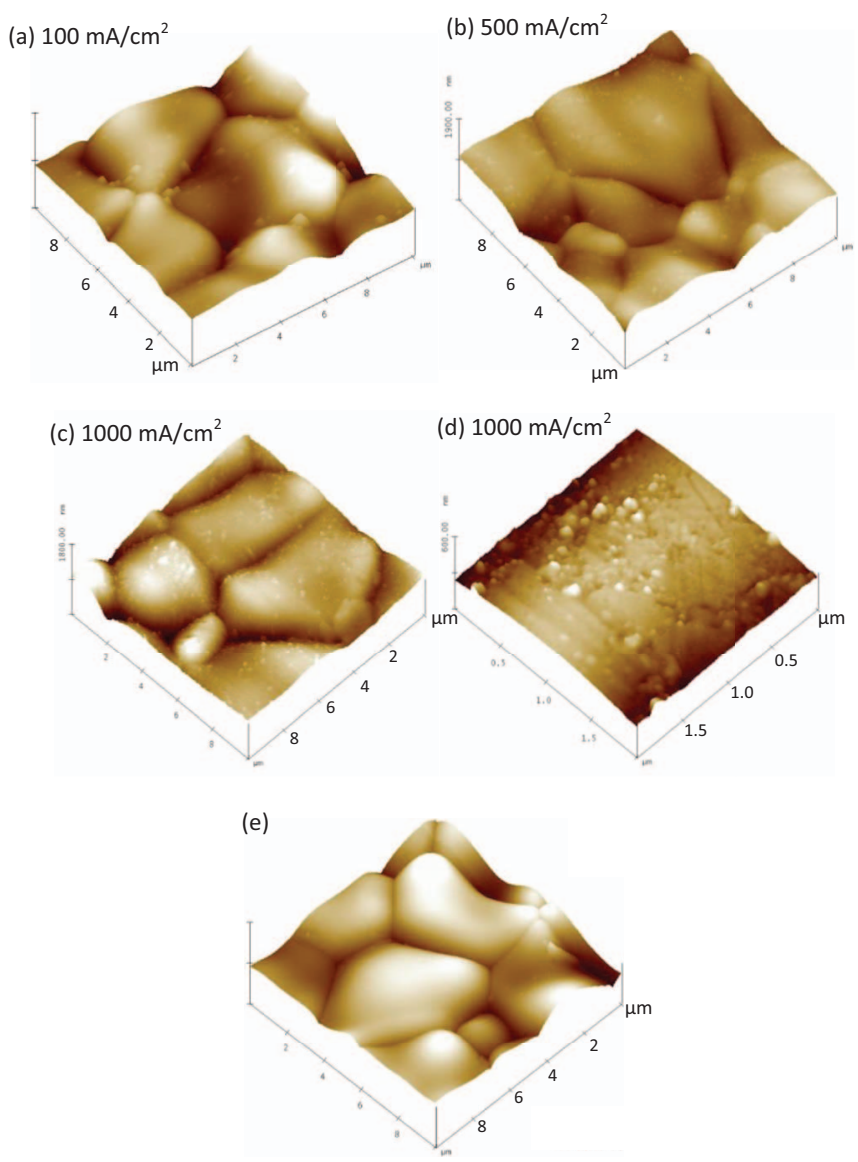

Figure 9. AFM micrographs of the in situ sintered LSM/GDC interfaces after polarized at (a) $100 \mathrm{mAcm}^{-2}$; (b) $500 \mathrm{mAcm}^{-2}$; (c, d) $1000 \mathrm{mAcm}^{-2}$ and $800^{\circ} \mathrm{C}$ for $3 \mathrm{~h}$. In situ assembled LSM electrode after polarization treatment was removed by $\mathrm{HCl}$ treatment. GDC electrolyte surface without polarization treatment is given in (e).

$0.10 \Omega \mathrm{cm}^{2}$ after polarization at $1000 \mathrm{mAcm}^{-2}$ for $3 \mathrm{~h}$. This is very close to $0.12 \Omega \mathrm{cm}^{2}$ observed on the pre-sintered LSCF/GDC interface (Fig. 10), indicating that the electrochemical activity of the in situ assembled LSCF/GDC interface is almost the same as that of the pre-sintered LSCF/GDC interface. The contact marks or clusters are also formed on the GDC electrolyte surface after polarization at 1000 $\mathrm{mA} \mathrm{cm}{ }^{-2}$ (Figs. 12b and 12c). The size of contact marks is $\sim 0.6 \mu \mathrm{m}$ and distributed on the GDC electrolyte surface. However, the number and density of the contact marks appear to be much lower than that observed on the in situ assembled LSM/GDC interface under similar polarization conditions (see Figs. 9c and 9d).

Thermally vs electrochemically induced interfaces. - The observation of convex contact rings for the pre-sintered LSM/YSZ, LSM/GDC and LSCF/GDC electrode/electrolyte systems as shown in this study indicates the formation of electrode/electrolyte interface induced under the high temperature sintering process. A study by Horita et al. showed that convex rings on the YSZ electrolyte surface have significantly higher concentrations of manganese as compared to that of the flat boundary between $\mathrm{LaMnO}_{3}$ and $\mathrm{YSZ}$ and an amorphous layer exists at the $\mathrm{LaMnO}_{3}$ film/YSZ interface due to cation interdiffusion of $\mathrm{La}, \mathrm{Y}, \mathrm{Zr}$ and $\mathrm{Mn} .{ }^{57}$ Tan et al. prepared $\mathrm{La}_{0.9} \mathrm{Ba}_{0.1} \mathrm{MnO}_{3}$ film on single crystal YSZ substrate by magnetron sputtering and also observed a formation of amorphous intermediate layer with thickness of about $3 \mathrm{~nm}$ between the film and YSZ. ${ }^{58}$ Thus, the formation of convex contact rings at the pre-sintered interfaces can be contributed to the cation interdiffusion between LSM and LSCF perovskite electrodes and YSZ and GDC electrolytes, thermally induced under high
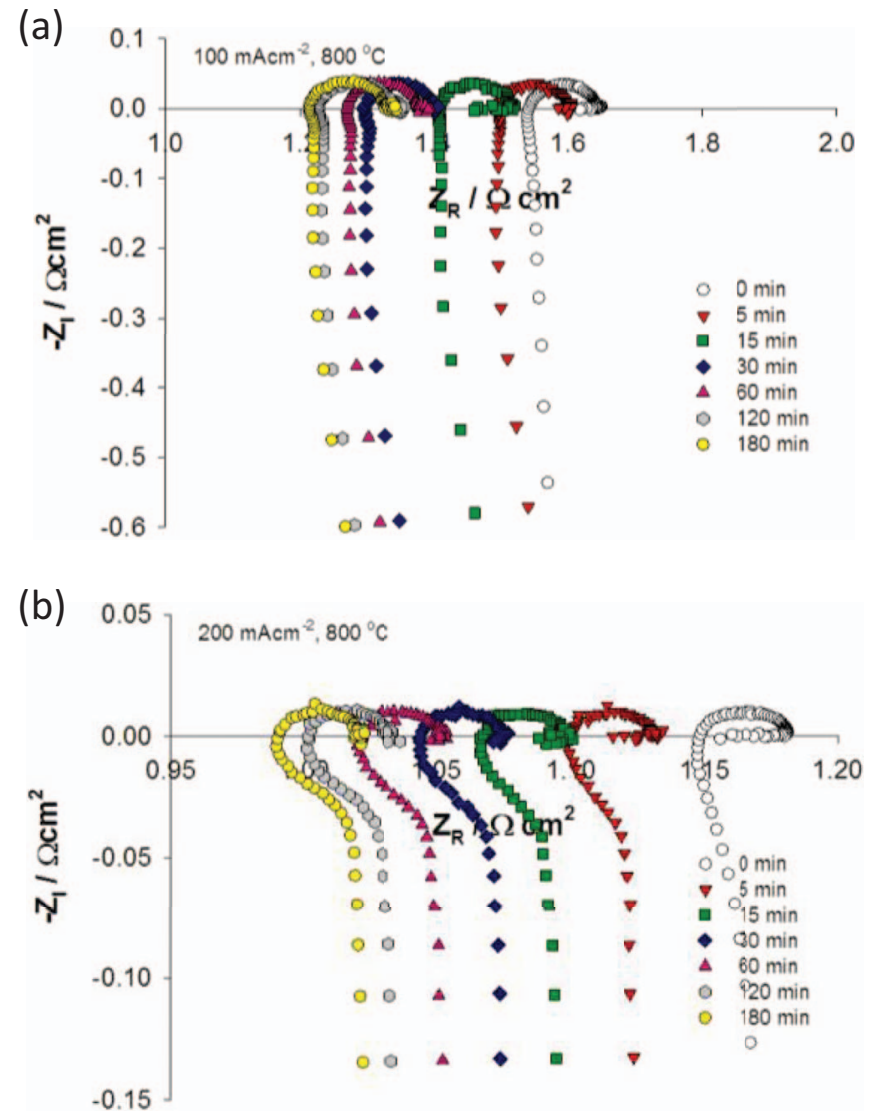

Figure 10. Impedance curves of oxygen reduction on pre-sintered LSCF cathodes on GDC electrolyte as a function of cathodic polarization currents: (a) $100 \mathrm{mAcm}^{-2}$ and (b) $200 \mathrm{mAcm}^{-2}$ at $800^{\circ} \mathrm{C}$.

temperatures. The size of the contact convex rings is in agreement with the particle size of pre-sintered LSM and LSCF electrodes after the high temperature sintering process.

The significant reduction in $R_{\mathrm{E}}$ for the reaction on pre-sintered LSM/YSZ and LSM/GDC and corresponding changes in the morphology and topography of the convex contact rings are consistent with early results that convex contact rings are the TPB for the $\mathrm{O}_{2}$ reduction reaction. ${ }^{23}$ Morphology change of the convex rings at the pre-sintered LSM/YSZ and LSM/GDC interfaces is most likely due to the incorporation of oxygen and/or cation interdiffusion such as manganese between LSM and YSZ or GDC as the convex rings at the interface provide the short diffusion paths, as shown by the isotopic oxygen exchange and SIMS studies. ${ }^{17,59,60}$ On the other hand, the negligible changes in the convex contact rings at the pre-sintered LSCF/GDC interface indicate that $\mathrm{O}_{2}$ reduction reaction occurs predominantly in the electrode bulk away from the TPB due to its high MIEC properties. ${ }^{50,61}$ In contrast with the substantial activation effect of the cathodic polarization on the electrochemical activities of pre-sintered LSM electrodes, the changes in $R_{\mathrm{E}}$ for the $\mathrm{O}_{2}$ reduction reaction on pre-sintered LSCF electrodes under the cathodic polarization current passage are negligible (Fig. 10). This is in an excellent agreement with the negligible effect of the polarization on the morphology of the convex contact rings at the pre-sintered LSCF/GDC interface.

Different to the situation in the pre-sintered electrode/electrolyte interfaces, there is no pre-formed interface between the electrode and electrolyte before the cathodic polarization passage in the case of the in situ assembled electrodes. The interfaces could not be thermally induced or formed at the test temperature used in this study, e.g., $800^{\circ} \mathrm{C}$. This is supported by the clean and smooth surface of YSZ and GDC electrolyte prior to the polarization treatment (Figs. 5e and 9e). 

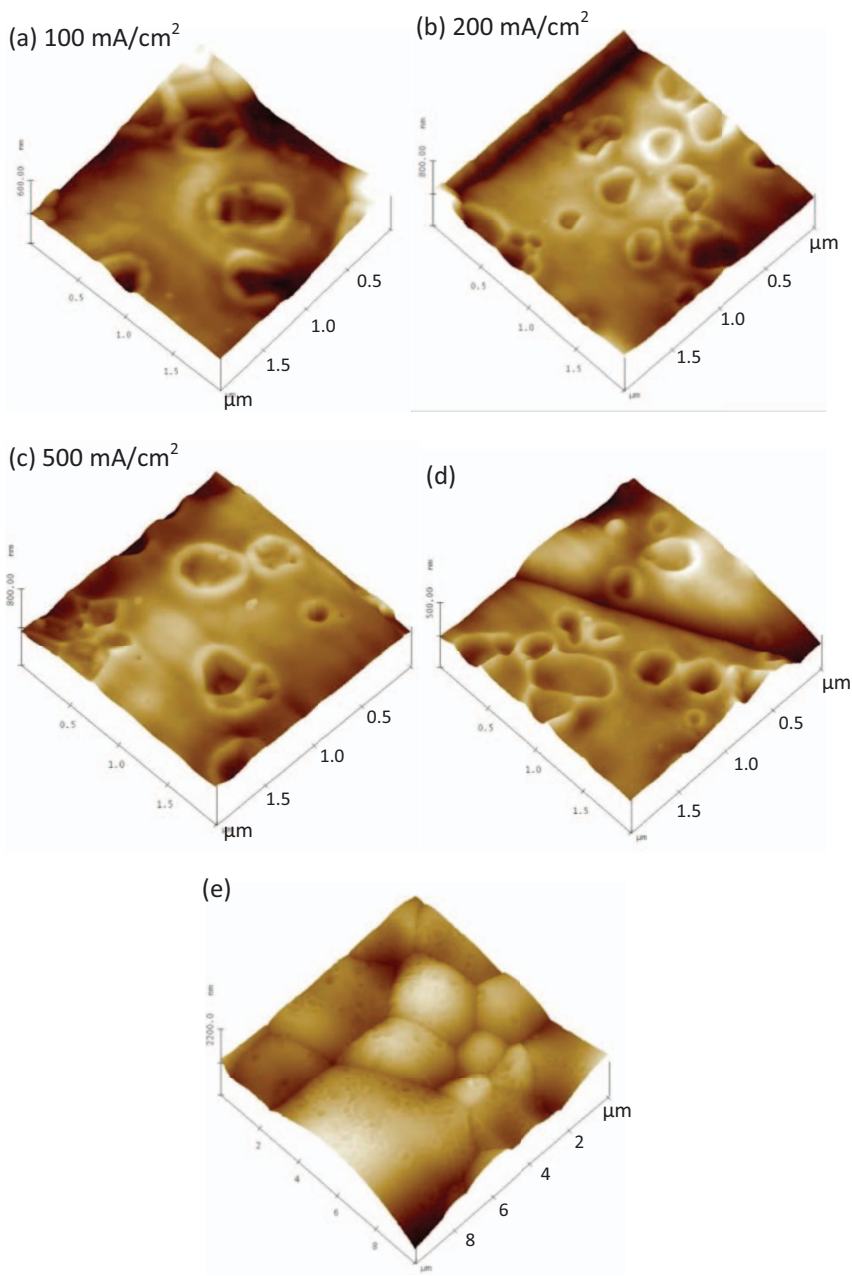

Figure 11. AFM micrographs of the pre-sintered LSCF/GDC interfaces after polarized at (a) $100 \mathrm{mAcm}^{-2}$; (b) $200 \mathrm{mAcm}^{-2}$; (c) $500 \mathrm{mAcm}^{-2}$ and $800^{\circ} \mathrm{C}$ for $3 \mathrm{~h}$. LSCF electrode was sintered at high temperatures and was removed by $\mathrm{HCl}$ treatment after polarization treatment. GDC in contact with pre-sintered LSCF electrode before the polarization treatment was given in $(\mathrm{d}, \mathrm{e})$.

The gradual increase of the contact marks and clusters on the YSZ and GDC electrolyte surface of the in situ assembled LSM also indicates that the interfaces between the in situ assembled electrodes such as LSM and LSCF and electrolytes such as YSZ and GDC can only be formed or induced by the cathodic polarization conditions, i.e., the electrochemical processes associated with the $\mathrm{O}_{2}$ reduction reaction. A recent in operado study by Fang et al. using synchrotron-bases ambient XPS showed that the oxygen-ion incorporation at the surface of ceria for water splitting and hydrogen evolution reactions is fast. ${ }^{62}$ Such formation of the interface is clearly affected by the oxygen activity at the contact points between the electrode and electrolyte as shown by the increased contact clusters with the increase of the cathodic polarization current (Figs. 5 and 9).

The emerging of the contact clusters at the in situ assembled LSM/YSZ, LSM/GDC and LSCF/GDC interfaces could be explained based on the mechanism of the incorporation of oxygen and the cation interdiffusion between electrode and electrolyte, similar to that of the thermally induced interface on pre-sintered electrode/electrolyte systems. Electrochemical polarization can promote the interaction between the electrode and electrolyte in SOFCs and has significant effect on the surface segregation and surface composition of perovskite oxide electrodes. Mutoro et al. studied the surface composition of $(\mathrm{LaSr}) \mathrm{CoO}_{3}$ thin film by in situ synchrotron-based XPS and observed the surface enrichment of SrO-like and $\mathrm{CoO}_{\mathrm{x}}$-like phase under cathodic polarization. ${ }^{32}$ In the case of LSM, Huber et al. observed the

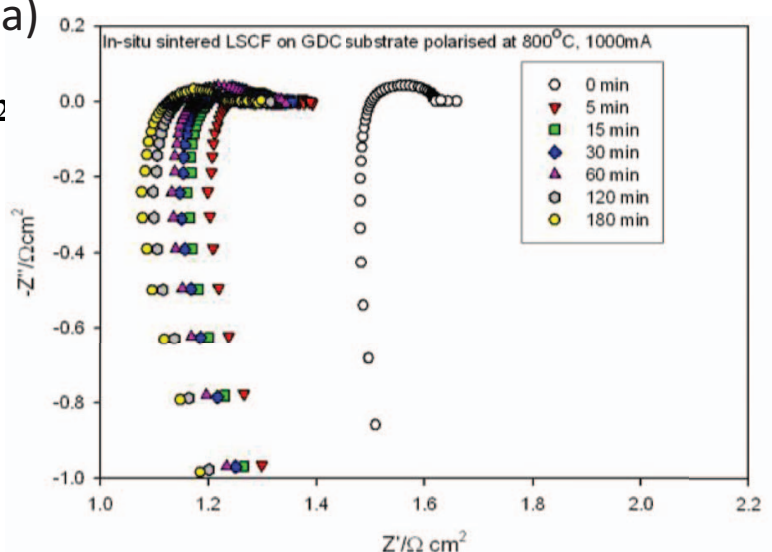

(b)

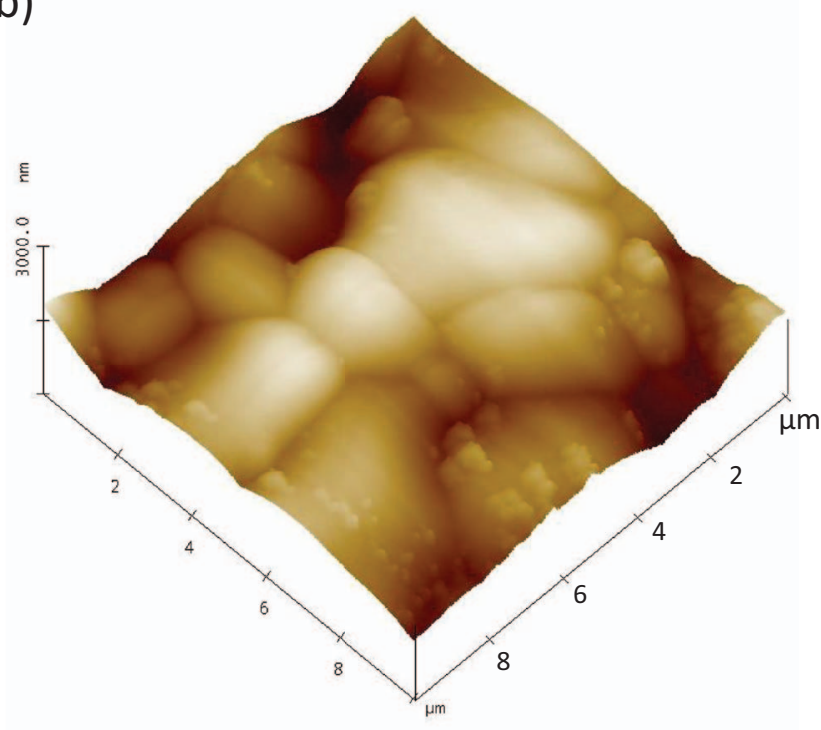

(c)

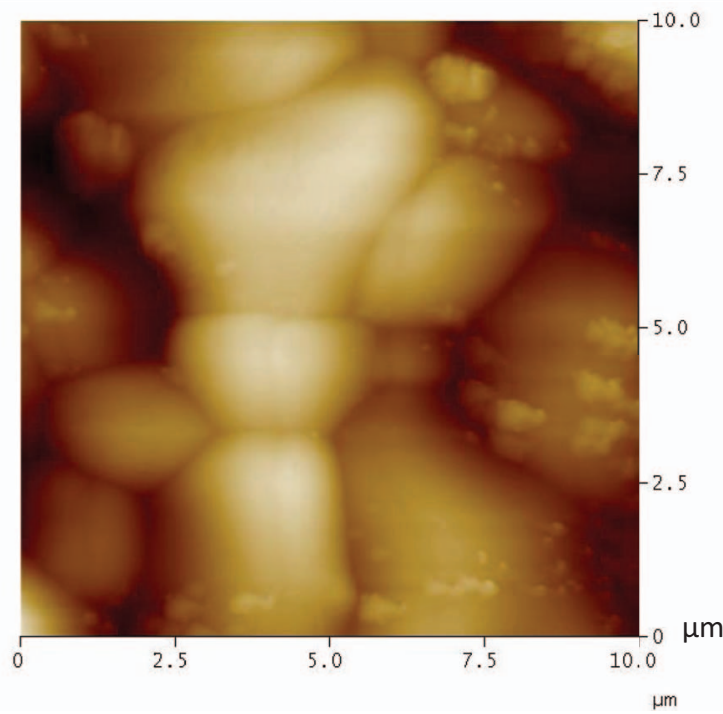

Figure 12. (a) Impedance curves of oxygen reduction on the in situ sintered LSCF cathodes on GDC electrolyte as a function of cathodic polarization currents at $1000 \mathrm{mAcm}^{-2}$ and $800^{\circ} \mathrm{C}$, and (b, c) Corresponding AFM micrographs after the polarization treatment. LSCF electrode was removed by $\mathrm{HCl}$ treatment.

depletion of the LSM surface in both $\mathrm{Sr}$ and Mn under cathodic polarization, but also found that cathodic polarization promotes the spreading or diffusion of segregated $\mathrm{Sr}$ and $\mathrm{Mn}$ onto the electrolyte. ${ }^{33}$ The diffusion of manganese oxide out of the LSM electrode onto the YSZ electrolyte surface under the influence of cathodic polarization has also been reported by Backhaus-Ricoult et al. ${ }^{63}$ We studied the effect of polarization on the chemical reactivity between $\mathrm{Ba}_{0.5} \mathrm{Sr}_{0.5} \mathrm{Co}_{0.8} \mathrm{Fe}_{0.2} \mathrm{O}_{3-\delta}$ (BSCF) and GDC and observed that under cathodic polarization 
conditions, the reaction between BSCF and GDC occurs at temperatures as low as $700^{\circ} \mathrm{C}$, forming Ba-containing particles at the interface. ${ }^{64}$

In the case of in situ assembled LSM electrodes, $\mathrm{O}_{2}$ reduction reaction can only take place at the TPB, similar to pre-sintered LSM electrodes. Thus, the incorporation of oxygen and the cation interdiffusion between $\mathrm{La}, \mathrm{Y}, \mathrm{Zr}, \mathrm{Mn}$ and $\mathrm{Ce}$ would occur at the contact points between the in situ assembled fine LSM particles and YSZ or GDC electrolyte, which in turn induces the morphology change at the interface, similar to the formation of convex contact rings in the case of pre-sintered LSM/YSZ and LSM/GDC interface. The formation of contact clusters is clearly due to the much smaller particle size of the in situ assembled LSM electrode coatings, as compared to the agglomerated LSM grains of the pre-sintered one. Very different to the in situ assembled LSM electrodes, the number and distribution of the contact cluster on the in situ assembled LSCF electrode on GDC electrolyte are much smaller (Fig. 12). This is most likely due to the fact that $\mathrm{O}_{2}$ reduction reaction on LSCF perovskites is not limited to the TPB. Consequently, the driving force for the oxygen incorporation and in particular the cation interdiffusion between $\mathrm{La}, \mathrm{Sr}$, Co and $\mathrm{Ce}$ at the interface contact points is much smaller under the cathodic polarization conditions, despite that it is well known that both $\mathrm{Sr}$ and Co are segregated to the LSCF surface. ${ }^{65}$ The substantial differences in the formation of the contact clusters on the GDC electrolyte for the reaction on the in situ assembled LSM and LSCF electrodes demonstrate that electrochemically induced interface formation is very much dependent on the nature of the electrode materials.

A most important observation from the present study is that despite the significant differences in the microstructure of the interfaces, the electrochemically induced interfaces behave very much like the thermally induced interfaces for the $\mathrm{O}_{2}$ reduction reaction. This is evidently supported by the similar polarization behavior between the pre-sintered LSM/YSZ, LSM/GDC and LSCF/GDC and the in situ assembled counterparts. For example, in the case of in situ assembled LSM/YSZ electrodes, the cathodic polarization current shows a significant activation effect on the electrocatalytic activity for $\mathrm{O}_{2}$ reduction reaction (Fig. 2), identical to the reaction on pre-sintered LSM/YSZ electrodes (Fig. 1). $R_{\mathrm{E}}$ of the in situ assembled LSM/YSZ interface after the polarization at $500 \mathrm{mAcm}^{-2}$ for $3 \mathrm{~h}$ is $0.4 \Omega \mathrm{cm}^{2}$, which is actually lower than $0.8 \Omega \mathrm{cm}^{2}$ for the $\mathrm{O}_{2}$ reduction reaction on the pre-sintered LSM/YSZ interface polarized under the same conditions. Similar electrochemical performance was also observed between pre-sintered and in situ assembled LSM/GDC and LSCF/GDC interfaces. This in turn implies that electrochemically induced interfaces and their profound effect on the electrocatalytic activities are important considerations in the fundamental understanding of the microstructure and electrochemical performance durability of the SOFC cathodes.

\section{Conclusions}

In this study, thermally and electrochemically induced electrode/electrolyte interfaces were investigated on pre-sintered and in situ assembled LSM and LSCF electrodes on YSZ and GDC electrolytes. The results indicate that thermally induced interface is characterized by convex contact rings with depth of 100-400 nm and diameters in agreement with the particle size of pre-sintered LSM and LSCF electrodes. On the other hand, under cathodic polarization conditions, electrode/electrolyte interfaces can also be formed on the in situ assembled electrodes. Different to that of the pre-sintered electrode/electrolyte interfaces, the electrochemically induced interfaces are characterized by particle-shaped contact marks or clusters and the number and distribution of contact clusters depend on the cathoidc current density as well as the electrode and electrolyte materials. For example, the contact NP clusters on the in situ assembled LSCF/GDC interface are substantially smaller than that on the in situ assembled LSM/GDC interface due to the high MIEC properties of LSCF materials. The results indicate that the electrochemically induced interface is most likely caused by the incorporation of oxygen species and cation interdiffusion between electrode and electrolyte under the influence of cathodic polarization. The electrocatalytic activities of the electrochemically and thermally induced electrode/electrolyte interfaces for the $\mathrm{O}_{2}$ reduction reaction are comparable and similar, despite the substantial differences in the topography and microstructure of the interface.

\section{Acknowledgment}

I sincerely thank Dr Wang Wei and Ho Weiwen for the technical assistance in the electrochemical and AFM measurements. The work was mainly performed at the Nanyang Technological University, Singapore.

\section{References}

1. S. B. Adler, Chem. Rev., 104, 4791 (2004).

2. S. P. Jiang and S. P. S. Badwal, J. Electrochem. Soc., 144, 3777 (1997).

3. J. R. Wilson, M. Gameiro, K. Mischaikow, W. Kalies, P. W. Voorhees, and S. A. Barnett, Microscopy and Microanalysis, 15, 71 (2009).

4. V. C. Kournoutis, F. Tietz, and S. Bebelis, Solid State Ionics, 197, 13 (2011).

5. A. L. Soldati, L. Baque, H. Troiani, C. Cotaro, A. Schreiber, A. Caneiro, and A. Serquis, Int. J. Hydrog. Energy, 36, 9180 (2011).

6. Z.-P. Li, T. Mori, G. J. Aucheterlonie, J. Zou, J. Drennan, and M. Miyayama, Solid State Ionics, 191, 55 (2011).

7. Z.-P. Li, T. Mori, G. J. Auchterlonie, Y. Guo, J. Zou, J. Drennan, and M. Miyayama, Journal of Physical Chemistry C, 115, 6877 (2011).

8. Y. L. Liu, A. Hagen, R. Barfod, M. Chen, H. J. Wang, F. W. Poulsen, and P. V. Hendriksen, Solid State Ionics, 180, 1298 (2009).

9. S. Uhlenbruck, T. Moskalewicz, N. Jordan, H. J. Penkalla, and H. P. Buchkremer, Solid State Ionics, 180, 418 (2009).

10. Y. Chen, S. Chen, G. Hackett, H. Finklea, X. Y. Song, and K. Gerdes, Solid State Ionics, 204, 87 (2011).

11. Y. L. Liu, K. Thyden, M. Chen, and A. Hagen, Solid State Ionics, 206, 97 (2012).

12. T. Matsui, Y. Mikami, H. Muroyama, and K. Eguchi, J. Power Sources, 242, 790 (2013).

13. S. P. Jiang, J. Mater. Sci., 43, 6799 (2008).

14. J. R. Wilson, J. S. Cronin, A. T. Duong, S. Rukes, H. Y. Chen, K. Thornton, D. R. Mumm, and S. Barnett, J. Power Sources, 195, 1829 (2010).

15. E. Ivers-Tiffee, A. Weber, and D. Herbstritt, J. Eur. Ceram. Soc., 21, 1805 (2001).

16. R. A. De Souza, J. A. Kilner, and J. F. Walker, Mater. Lett., 43, 43 (2000).

17. T. Horita, K. Yamaji, N. Sakai, H. Yokokawa, T. Kawada, and T. Kato, Solid State Ionics, 127, 55 (2000)

18. T. Horita, K. Yamaji, N. Sakai, H. Yokokawa, and T. Kato, J. Electrochem. Soc., 148, J25 (2001).

19. T. M. Huber, M. Kubicek, A. K. Opitz, and J. Fleig, J. Electrochem. Soc., 162, F229 (2015).

20. J. Yang, H. Muroyama, T. Matsui, and K. Eguchi, J. Power Sources, 204, 25 (2012)

21. J. Yang, H. Muroyama, T. Matsui, and K. Eguchi, J. Power Sources, 236, 192 (2013).

22. S. J. Dillon, L. Helmick, H. M. Miller, L. Wilson, R. Gemman, R. V. Petrova, K. Barmak, G. S. Rohrer, and P. A. Salvador, J. Am. Ceram. Soc., 94, 4045 (2011).

23. S. P. Jiang and W. Wang, Electrochem. Solid State Lett., 8, A115 (2005).

24. T. Matsui, Y. Mikami, H. Muroyama, and K. Eguchi, J. Electrochem. Soc., 157, B1790 (2010).

25. A. Mitterdorfer and L. J. Gauckler, Solid State Ionics, 111, 185 (1998).

26. C. Clausen, C. Bagger, J. B. Bildesorensen, and A. Horsewell, Solid State Ionics, 70, 59 (1994)

27. S. P. Jiang, J. P. Zhang, and K. Foger, J. Eur. Ceram. Soc., 23, 1865 (2003)

28. Y. Chen, L. Yang, F. Ren, and K. An, Scientific Reports, 4, 5179 (2014).

29. W. Wang and S. P. Jiang, J. Solid State Electrochem., 8, 914 (2004).

30. S. P. Jiang and J. G. Love, Solid State Ionics, 138, 183 (2001).

31. W. Wang and S. P. Jiang, Solid State Ionics, 177, 1361 (2006).

32. E. Mutoro, E. J. Crumlin, H. Popke, B. Luerssen, M. Amati, M. K. Abyaneh, M. D. Biegalski, H. M. Christen, L. Gregoratti, J. Janek, and Y. Shao-Horn, Journal of Physical Chemistry Letters, 3, 40 (2012).

33. A. K. Huber, M. Falk, M. Rohnke, B. Luerssen, M. Amati, L. Gregoratti, D. Hesse, and J. Janek, J. Catal., 294, 79 (2012).

34. S. Carter, A. Selcuk, R. J. Chater, J. Kajda, J. A. Kilner, and B. C. H. Steele, Solid State Ionics, 53-56(Part 1), 597 (1992).

35. M. Katsuki, S. Wang, M. Dokiya, and T. Hashimoto, Solid State Ionics, 156, 453 (2003).

36. L. W. Tai, M. M. Nasrallah, H. U. Anderson, D. M. Sparlin, and S. R. Sehlin, Solid State Ionics, 76, 259 (1995)

37. L. W. Tai, M. M. Nasrallah, H. U. Anderson, D. M. Sparlin, and S. R. Sehlin, Solid State Ionics, 76, 273 (1995)

38. G. C. Kostogloudis, G. Tsiniarakis, and C. Ftikos, Solid State Ionics, 135, 529 (2000).

39. H. Uchida, S. Arisaka, and M. Watanabe, Electrochem. Solid State Lett., 2, 428 (1999).

40. F. F. Wang, M. E. Brito, K. Yamaji, D. H. Cho, M. Nishi, H. Kishimoto, T. Horita, and H. Yokokawa, Solid State Ionics, 262, 454 (2014).

41. B. A. Fan, J. B. Yan, and W. P. Shi, J. Eur. Ceram. Soc., 30, 1803 (2010). 
42. S. P. Jiang, J. Appl. Electrochem., 34, 1045 (2004).

43. S. P. Jiang, J. Power Sources, 124, 390 (2003).

44. S. McIntosh, S. B. Adler, J. M. Vohs, and R. J. Gorte, Electrochem. Solid State Lett., 7, A111 (2004)

45. M. A. Haider and S. McIntosh, J. Electrochem. Soc., 156, B1369 (2009).

46. T. Kenjo and M. Nishiya, Solid State Ionics, 57, 295 (1992).

47. F. L. Liang, J. Chen, J. L. Cheng, S. P. Jiang, T. M. He, J. Pu, and J. Li, Electrochemistry Communications, 10, 42 (2008).

48. B. Liu, H. Muroyama, T. Matsui, K. Tomida, T. Kabata, and K. Eguchi, J. Electrochem Soc., 157, B1858 (2010)

49. Y. H. Liu, F. Z. Wang, B. Chi, J. Pu, L. Jian, and S. P. Jiang, J. Alloy. Compd., 578, 37 (2013).

50. S. P. Jiang, Solid State Ionics, 146, 1 (2002)

51. A. Mai, V. A. C. Haanappel, S. Uhlenbruck, F. Tietz, and D. Stover, Solid State Ionics, 176, 1341 (2005).

52. J. M. Bae and B. C. H. Steele, Solid State Ionics, 106, 247 (1998).

53. D. Beckel, U. P. Muecke, T. Gyger, G. Florey, A. Infortuna, and L. J. Gauckler, Solid State Ionics, 178, 407 (2007).

54. C. J. Fu, K. N. Sun, N. Q. Zhang, X. B. Chen, and D. R. Zhou, Electrochim. Acta, 52, 4589 (2007).
55. A. Lanzini, P. Leone, M. Santarelli, P. Asinari, M. Cali, and R. Borchiellini, J. Fuel Cell Sci. Technol., 6 (2009).

56. B. C. H. Steele and J. M. Bae, Solid State Ionics, 106, 255 (1998).

57. T. Horita, T. Tsunoda, K. Yamaji, N. Sakai, T. Kato, and H. Yokokawa, Solid State Ionics, 152, 439 (2002)

58. W. S. Tan, H. O. Wang, P. Dai, H. P. Wu, X. S. Wu, Q. J. Jia, G. J. Hu, and J. Gao, Physica B, 406, 4115 (2011).

59. T. Horita, T. Shimonosono, H. Kishimoto, K. Yamaji, M. E. Brito, Y. Hori, and H. Yokokawa, Electrochem. Solid State Lett., 13, B135 (2010).

60. T. Horita, K. Yamaji, N. Sakai, X. P. Xiong, T. Kato, H. Yokokawa, and T. Kawada, J. Power Sources, 106, 224 (2002).

61. A. Esquirol, N. P. Brandon, J. A. Kilner, and M. Mogensen, J. Electrochem. Soc., 151, A1847 (2004).

62. Z. L. A. Feng, F. El Gabaly, X. F. Ye, Z. X. Shen, and W. C. Chueh, Nature Communications, 5, 4374 (2014).

63. M. Backhaus-Ricoult, K. Adib, T. S. Clair, B. Luerssen, L. Gregoratti, and A. Barinov, Solid State Ionics, 179, 891 (2008).

64. H. Yung, L. Jian, and S. P. Jiang, J. Electrochem. Soc., 159, F794 (2012).

65. L. Zhao, J. Drennan, C. Kong, S. Amarasinghe, and S. P. Jiang, Journal of Materials Chemistry A, 2, 11114 (2014). 